\title{
The Gold of the Celts
}

\author{
Christoph J. Raub
}

A

LREADY from the cover of this remarkable book by the French archaeologist Christiane Eluère, we suspect that something special must be hidden inside: it depicts the famous 'Pegasus' of the diadem of the 'Princess of Vix', riding across a field of filigree and granulation. Could there be a better intimation of the book's contents - a vision of the author sitting on 'Pegasus', discussing the highs and lows of Celtic gold's high tech? Another glance at the cover after reading the section on the 'Princess of Vix' confirms that the horse must be patterned after one of those stubby Gallic animals which in later years helped Gaius Julius Caesar, in command of an army of German mercenaries, to conquer Eluère's ancestors at Alesia. The symbolism could be extended further: the reviewer's copy was in German, his mother tongue is German - but he does not ride horses!

In the first chapter, 'Myth and Reality', Eluère sets the scene in that masterly way which she uses throughout the book, both in the text and in the choice of photographs: the juxtaposition of myth with archeological evidence, and technology with aesthetics. The reviewer discovered here for the first time Lucretius' description of the reduction
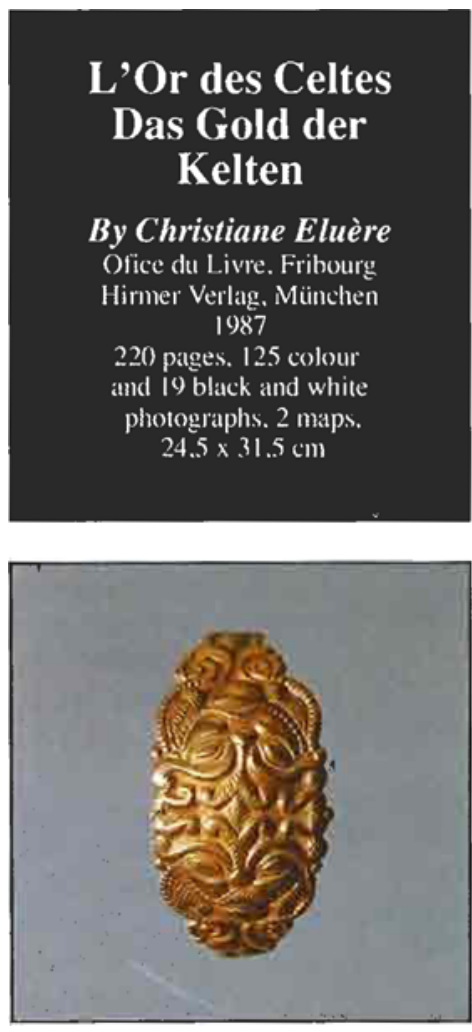

the objects is given. What a tedious task it must have been to collect all those data hidden in the maquis of the international specialist literature!

The chapter moves on to cover the period of the tumuli of northem Europe, around $1200-1100 \mathrm{BC}$. Here the reviewer enjoyed the remark about the modest amount of jewellery found in ladies' graves. Apparently the Celtic warriors used up all the gold for themselves and left little for their ladies! The titles of the sections give a good idea of the topics covered in this chapter: 'Arms Made From Gold', 'Gold and Religion', 'The Attraction of Water', and 'Gold and the Sun'. The representations of aquatic birds like ducks, swans, etc. are frequent in the decorative art of the Bronze Age, and more than 100 miniature gold figures of boats are known from this period. The big gold cones of Schifferstadt, Ezelsdorf and Avanton receive their proper share of attention, as do the lunulae, arm and neck rings.

From Chapter III ('The Gold of the Early Celtic Tombs') onwards, even a modern metallurgist is impressed by the synthesis of aesthetics and consummate skill shown by the Celtic goldsmiths during the Hallstatt, of ores with charcoal - the forest-fire theory - which today's science considers to be wrong, but which in Lucretius' poems reads very nicely. Here too, we find Pliny's description of gold's elemental properties, most of them still valid today in the age of the electron microprobe. Eluère devotes one succinct page to the question of the impurity profiles of gold found in primary or secondary deposits throughout Europe, without getting lost in too many detailed figures that would bore the non-technical reader without a background in metallurgy. Very interesting, too, is the section on 'The Legendary Gold of the Celts', which even covers such little-known artifacts as touchstones. The French ones, naturally, were identified by Christiane Eluère herself (see Gold Bull., 1986, 19(2), 58-61).

Chapter ll, 'The Goldsmiths' Art Before the Celts', begins with a reference to the Hyperboreans, who lived 'hinter den Wolkenbergen im Märchenland' (this is Herodotus, and not a quotation from a 1960's U.S. advertisement for the VW Beetle), touches on the Varna treasures and figurines in general, and tells the mystery story of the megalithic gold pearls found in the Pauilhac tomb. Again, in nearly all cases, the composition of and later La Tene, periods. This is illustrated in detailed colour photographs that even specialists have rarely seen before.

Understandably, the Celtic neckrings, or torcs, are discussed in detail, since some of them are treasures of world significance (see Gold Bull., 1987, 20(1/2), 22-37).

A section entitled 'The New Drinking Habits' is found in this book too - although not in Guide Michelin. In any case, the savoir vivre of the Celts is certainly linked with the development of their arts and technology. Evidence of this is the observation that many important Celtic sites are found in today's famous wine regions: Burgundy (Vix), Baden-Württemberg (Hochdorf) and not to forget Franken (Würzburg-Marienfeste). A party given by a Celtic prince really must have been something!

Chapter IV, 'The New Celtic Aristocraty in the 5th and the their own skills with influences from the surrounding cultures. In the book a wide variety of objects are presented and discussed. The absolute highlight, illustrated with superb detailphotographs, is the group of Celtic decorative helmets, especial4th Centuries BC', shows how the Celtic artists amalgamated 

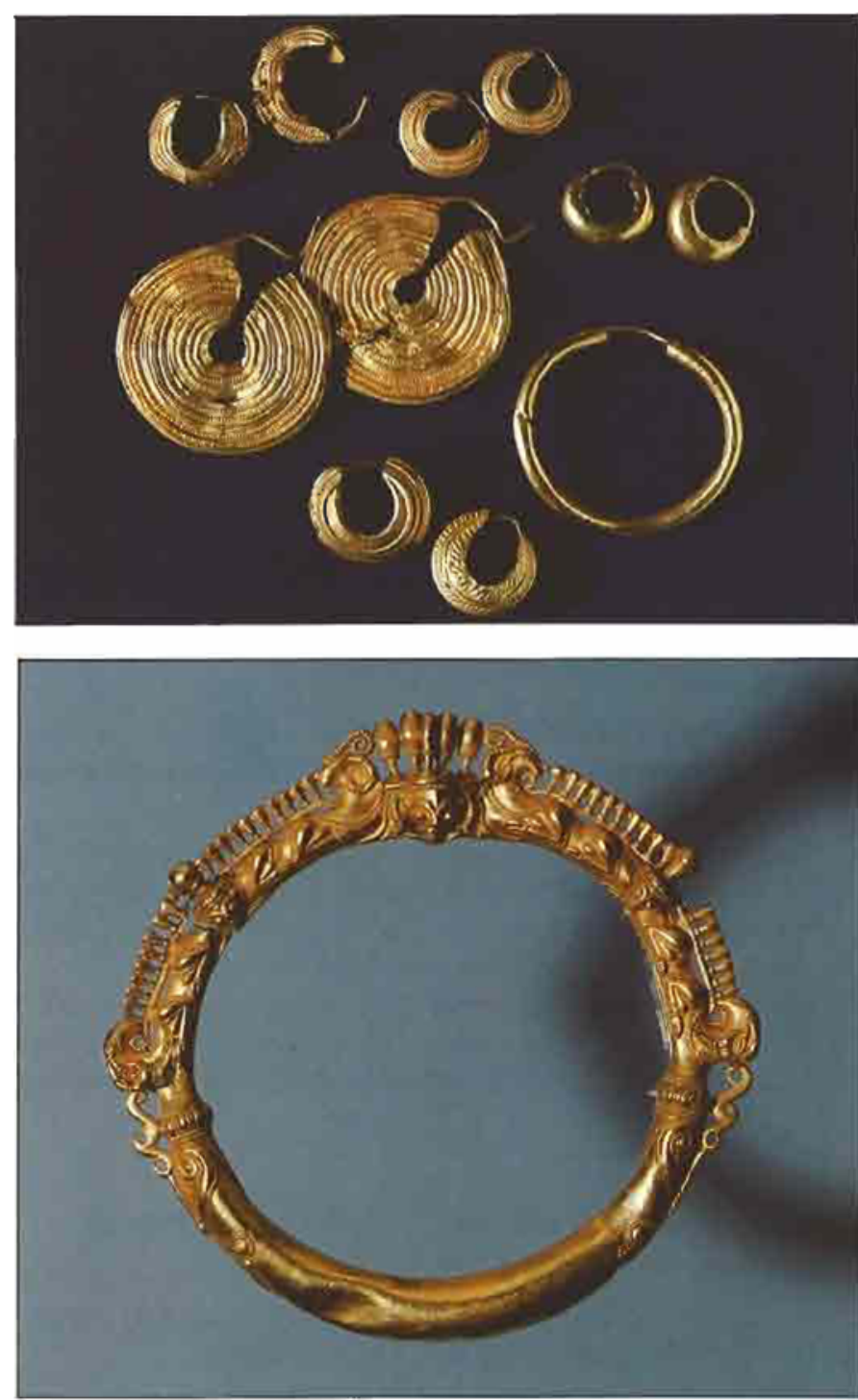

ly the one from Les Perrats near Agris. Just as impressive are the treasures of the Celtic princesses of the Rhinelands, especially those from Reinheim and Waldalgesheim. The latter is so important that its name is now applied to an entire period in Celtic art (Waldalgesheim style).

The last and fifth chapter, 'The Treasures from the Last Centuries BC', deals with the notorious treasure of Tolosa, or 'Aurum Tolosanum', which, according to Strabo, originated from the sacking of Delphi by the Celtic Tectosages.

This is followed by sections on Celtic coinage, in which archaeological results are always interspersed with historical references and technological information. One slight error has crept into the discussion of how coin blanks were produced: it is claimed that the Celts weighed out separately the exact amount of metal needed for each coin, and produced the blanks by casting. In practice however, it is impossible to cast the exact weight (even approximately) by pouring hot melt into the coin

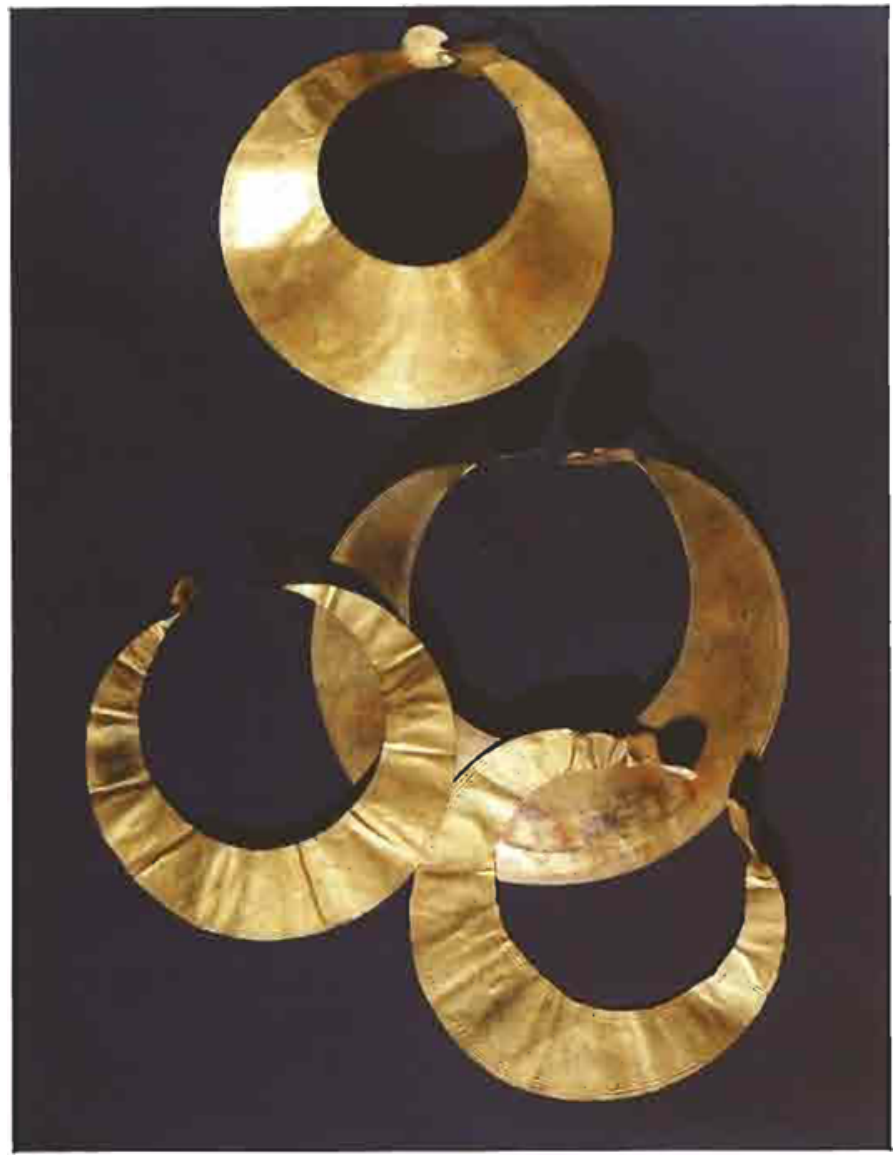

Left, and opposite page: Bracelet and ring from Rodenbach, near Kaiserslautern, Germany (5th century BC). Historisches Museum der Pfalz, Speyer

Top left: Selection of 5 th century BC earrings from the Champagne region of France, and, above: Early Bronze Age Lunules from northern France. Museé des Antiquities nationales, Saint-Germain-en-Laye

mould, as is stated in many archeological articles on coin production.

The closing chapter, 'The Gold of the Celts and the Antique World' is an impressive discussion of the influence of gold on a culture and a society. Many of the deductions arrived in it are certainly not limited to Celtic culture but are valid for most civilisations.

This beautiful book is not only a scholarly reference work on the history and technology of Celtic gold for the archeologist, the historian, the archaeometrist or the metallurgist, but it is also entertaining and fascinating reading for anyone interested in the civilizations of antiquity. Furthermore, it contains a wealth of ideas for the practical jeweller, the craftsman and/or the artist.

Unfortunately the book is only available in French or German, but it is hoped that an English edition will be published soon. 